Teaching speaking skills at Sudanese schools: Teachers' perceptions

Ahmed, Sami Hussein A.

Majmaah Univeristy, Saudi Arabia (Samihussein40@hotmail.com; komer307@gmail.com)

\title{
Abstract
}

The study aims at analyzing speaking activities as presented by the textbook, and reviewing teachers' perceptions towards teaching speaking. To achieve the set aims: textbook analysis (Mc Cready, 1975; Paulston, 1972; Morrow, 1981) criteria were used, and a questionnaire for teachers. The study found that speaking activities presented by the textbook are very few and not the ideal one. Further, teachers' reacted negatively to the speaking activities in the textbook and less attention has been given to teaching speaking.

Keywords: SPINE; speaking; activities; skills 


\section{Teaching speaking skills at Sudanese schools: Teachers' perceptions}

\section{Introduction}

Speaking, in Sudan, and specifically, at the basic level is a problematic one. Pupils are unable to speak or communicate freely, even in response to a simple question. They always prefer to express their ideas in Arabic. Several studies have pointed out the recent deterioration of the standard of English in Sudan. Moreover, the majority of studies published on the subject address only specific aspects of teaching reading, writing, and grammar (Nafisa, 2004; Ishraga, 2000; Aisha, 2006). There is no common ground for any approach for teaching speaking. Speaking classes are not systematic because no methods of teaching have provided about which speaking skills or language input should be used. Therefore, this study tries to investigate teaching speaking skill at Sudanese Basic schools, and the material presented by textbook.

\subsection{Objectives of the study}

The purpose of this study is to analyze the features of speaking activities presented by the textbook. It examines teachers' perceptions towards teaching speaking and activities presented by the textbooks.

\subsection{Study questions}

$>$ What are the features of speaking skills activities in SPINE (Sudan Practical Integrated National English) series?

What are the perceptions of teachers' towards teaching speaking and activities presented by the textbooks?

\section{Literature review}

Suleiman (2002) investigated variables responsible for stimulation of oral communication fluency in the EFL in four Sudanese universities. The study surveyed the intensity and effectiveness of the students' exposure to speech provoking visual stimuli, task and interesting activities that contribute to the language content. The study reached a conclusion that students' reluctance to oral contribution can be attributed to the following reasons: Lack of proper stimulation based on interesting authentic context, poor interactive linguistic input, and large classes and teachers centered mode of instruction. Ishraga (2001) evaluated SPINE in terms of its objectives, content, practice, illustration, and format at basic level in Aljazeera and Khartoum State. The study concluded that the book is not an ideal one and improvement should be leveled concerning the content, practice, illustration and format.

Another study conducted by Kim (2003) aimed to identify the types of speaking assessment task used by Korean junior secondary school English teachers and the ways in which those assessments were administered, it investigate Korean EFL classrooms which affect assessment of speaking. The conclusion is reached that although Korean teachers need to have assistance and encouragement to try new ways of communicative assessment in their EFL classrooms, they need to make themselves aware of the shift in social and educational needs and to make conscious and persistent efforts to introduce more communicative speaking assessment in spite of practical difficulties. Abdelmuttalib (2004) investigated the teaching of English alphabet in Sudan through SPINE 1 in Khartoum basic schools. It aimed to check the method of teaching followed by SPINE in teaching English alphabet, in terms of teaching reading and writing English alphabet. The study revealed that SPINE does not follow an appropriate method in teaching English alphabet and teachers did not receive adequate training to teach English alphabet. 
Aisha (2006) investigated the training courses of English language teachers in Khartoum basic level in terms of its adequacy and quality. The study concluded that teachers are not adequately trained and this could affect the standard of pupils' achievements. Nafisa (2004) aimed to investigate the errors in tenses committed by secondary school students in Khartoum. The study found that SPINE is poor in terms of teaching grammatical points and gradation. Most of the previous studies conducted in Sudanese context focused on certain aspects of skills: reading, and writing mainly. No or few researches have been conducted on speaking skill, especially at basic levels. Besides using a questionnaire, the study also analyze the features of speaking activities in the textbook which make it quite different form it predecessors. It hopes that the findings of this study may lead to a better teaching of speaking skills and helping students to be better speakers. It is also an insight to courses planners to improve the speaking activities in SPINE series.

\section{The study}

\subsection{The material of this study}

The material of this study consists of SPINE series, namely: book 1, book 2, and book 3. SPINE is used in Sudanese basic schools. For the textbook analysis (Mc Cready, 1975; Paulston, 1972; Morrow, 1981) criteria were used. SPINE is the only textbook used in the govermental schools: SPINE 1, 2, and 3 for basic schools, and 4,5 , and 6 for secondary schools.

\subsection{Teachers' Questionnaire}

The teacher's questionnaire (TsQ) consist of 31 items. The teachers' questionnaire was administered to 40 teachers in hand, and was given a up to three days to respond to the questions. It is divided into three parts:

$>\quad$ Part A: included 8 statements, surveying teacher's attitudes towards speaking, with likert five point scale: (Strongly agree, agree, undecided, disagree, and strongly disagree).

$>$ Part B: included 8 statements, surveying teachers' self-evaluation of speaking based in-class-tasks, with likert five point scale: (Always, often, sometimes, rarely, and never ).

$>\quad$ Part C: included 15 statements, surveying teachers' attitudes to teaching speaking in SPINE, with likert five point scale: (Strongly agree, agree, undecided, disagree, and strongly disagree).

\subsection{Validity and reliabilty of the study}

A questionnaire or a test is valid if it is measure what is supposed to measure.To achieve the validitry of this questionnaire, it was piolted before its actual use to check the following:

$>\quad$ The clarity of the items and instruction sequences.

$>$ The flexibility and simplicity of items, and how far they related to the subject.

$>\quad$ The language used.

In statistics, reliability is the consistency of a set of measurements often used to describe a test. For the reliability of the questionnaires, the study used Cronbach's alpha. For the application of Cranach's alpha, the study used the SPSS. The result of alpha test was as the follows:

$$
\text { TsQ }=.09938
$$

The sample size of this study was selected randomly from a number of teachers at basic schools. 


\section{Results and discussion}

\subsection{Text book analysis}

Examining the course material under evaluation, it was found that terminal objectives have not been specified explicitly anywhere, but they were indicated implicitly in short introduction to the teacher's book. The course aimed at developing the pupils' speaking and listening competence (Teacher's book 2 and 3, pupil's book 1: viii; teachers' book 3). The designers did not define the degree of mastery; they only emphasized the mastery of the skills of speaking, with further modification left to the teacher to do it (Teacher's Book 3). A survey of the content of the units in the teacher's book would reveal that the course teaches both form and functions not as isolated lists of language elements, but as means to develop the communicative skills. At the beginning of each unit, the content is divided into three parts, the first specifies the function and notions, the second part specifies the structural elements that the course teaches and serves the first element, while the third specifies the skills practiced through each example.

Topics in SPINE (Sudan Practical Integrated National English) (3), Unit (3), Lesson (1):

$1 \quad$ (a) People who help us.

(b) Great men \& women.

2 Communicative skills listening \& speaking.

(a) Talking about jobs.

(b) Responding to simple question.

In SPINE (2) Unit (2)

1 Topics.

(a) The weather.

(b) Transport.

2 Communication skill

Talking about people, weather, advising someone not to do something.

The objective of the course emphasizes the communicative potential of the course, thus the course should reflect this by emphasizing communicative activities. A view at the content of course, show that the course designers have not chosen the right type of content because they specify grammatical structure and functions, giving priority to the grammatical structure taught with ultimate aim of developing the specified skills. Hence the course is not communicative.

In the same respect, Littlewood (1984) contends that the target language usage is necessary for the exposure of learners to some important input to achieve communicative competence. Therefore, it is necessary for teachers to get into the habit of addressing their pupils in English wherever possible even when they meet outside the classroom. On contrary to that, the SPINE series Teacher's book 1 (1997) advises the teacher to communicate first in Arabic.

\subsection{Dialogues}

Dialogues are most preferable type of context; they fulfill a whole range of functions in the language. Yet 
Teaching speaking skills at Sudanese schools: Teachers' perceptions

not any dialogue is suitable for teaching. McCready (1975) specified a number of criteria for dialogue, these are:

$>\quad$ It should be long enough to develop a believable conversation and short enough to the average students to memorize.

$>\quad$ The number of new items presented (vocabulary, structure) should be controlled.

$>\quad$ The exchange represented in dialogue should be natural; i-e it could take place between native speakers of English.

$>\quad$ (4) It should take into account the age and interests of the students.

SPINE series include only very few dialogues: There is no dialogue in SPINE One, there are six dialogues in SPINE Two, and very few dialogues in SPINE Three. They draw heavily on text as a presentation frame work, especially book 3 . This is not natural in any material claiming to be communicative; since dialogues are very essential for communication. Moreover the dialogue presented by the text book is not graded from controlled, less controlled to free creative language production. Dialogues in SPINE are mechanically repeated rather than talking about real events.

\subsection{Pictorial Devices}

Text books prepared for language teaching courses may contain two types of pictures: text pictures and class pictures. Text pictures are those appearing in the text itself. These can be either photographs or drawings. Class pictures are separately printed for classroom use. Mackey (1965) specified number of criteria concerning pictures. These are: clarity, specifity, natural color. In SPINE, very few of the pictures chosen are clear and specific in relation to the meaning they intend to introduce. The rest of the pictures are not clear and some of them are full of irrelevant details, e.g.: book 3 unit (4), lesson (8). The pictures are not motivating, and they are in an accurate in representing reality. Teacher's books do not offer enough guidance for the teachers to help them using the pictures to stimulate students to speak.

\subsection{Practice}

Paulston, (1972) attempts to classify various kinds of exercise into three types: mechanical, meaningful, and communicative. Proponents of the communicative approach believe that learning is a result of doing things. They maintain that by practicing communicative activities the learner can learn to communicate Morrow (1981). They suggest activities, which replicate as far as possible the process of communication so that practice of the forms of the target language can take place within a communicative framework. An exercise is more communicative if it possesses more of the central characteristics of communication. These are:

Information Gap - In real life, communication takes place between two or more people. The purpose of the communication is bridging the information gap (Morrow, 1981). Communicative drills since they replicate real communication should create information gaps so that learners would communicate to bridge these gaps (Lyons, 1986; Johnson, 1982; Morrow, 1981).

Choice - Another crucial characteristic of communication is that the participants have choice, both in terms of what they will say, and more particularly, how they will say it (Morrow, 1981). Communicative drills can cater for this element of communication by decreasing the amounts of control on the learners' response.

Reason or Purpose - In real life communication is usually carried out for purpose. Similarly, in communicative drills the students should be given a reason to communicate.

Integration - Language is rarely used in more at time, whereas skills are normally integrated in real life. Therefore, communicative exercises should also practice integrated skills (Byrne, 1981). 
Ahmed, S. H. A.

The material under analysis provides a wide variety of exercises and activities to practice the four skills and their components. In examining the communicative potential of the drills to see how they resemble natural communicative acts, the following are found:

A few involve an information gap, so the learner will have to communicate in order to bridge that gap.

$>$ The communicative exercises in the SPINE do not allow the student a certain amount of freedom in their responses, and that is a reason for classifying them as non-communicative.

Most of the communicative exercises given involve integration two or more skills together.

However it can be noticed that the exercises emphasize reading because most of them start by reading, especially SPINE 3. The number of exercises designed to practice the various skills do not vary considerably. Also it can be seen from the above, no skills are given the highest proportion of exercises. Listening and speaking are the ones that are given the least attention. Furthermore, speaking activities in SPINE emphasized repetition and accuracy; ultimately, they did not help pupils to achieve communicative competence in the target language. In addition, they are not graded from control to free creative use of the language, and may lead to pupils' boredom.

There is no role-play, information gap, challengers, which are core features in any communicative syllabus. SPINE series present the following activities:

\section{Table 1}

Checklists of speaking activities in SPINE

\begin{tabular}{lll}
\hline \multicolumn{1}{c}{ ACTIVITY } & Number of Activities & \\
\hline Listen, look and say & 33 & Objective of Activity \\
Listen and repeat & 15 & Pronunciation \\
Read a loud & 11 & Pronunciation \\
Point and say & 11 & Pronunciation \\
Answer the question & 35 & Pronunciation \\
Game & 4 & Communication \\
\hline \multicolumn{1}{c}{ SPINE2 } & & \\
Listen, look and say & 19 & Pronunciation \\
Dialogue & 5 & Functional and conversational expressions \\
Answer question & 40 & Pronunciation \\
Pair work + group work & 7 & Teaching point, increase opportunity for individual \\
& & practice \\
See the same sound & 1 & Pronunciation \\
See different sound & 1 & Pronunciation \\
\hline \multicolumn{1}{c}{ SPINE3 } & & \\
look and say & 14 & oral expression \\
Songs & 5 & Oral expression \\
Read & 20 & Pronunciation \\
Make sentence & 17 & Pronunciation \\
Ask and answer & 40 & Controlled conversations \\
Pair work & 5 & Teaching point increase opportunity for individual \\
& & practice \\
\hline
\end{tabular}

\subsection{Questionnaire analysis}

Teachers' Attitudes towards Speaking - 70\% of the teachers agreed that speaking is the most difficult of the four skills. This indicates that why teaching speaking at Sudanese basic level is relatively neglected. $90 \%$ of teachers felt that pupils were reluctant to speak because they fear making mistakes. Pupils need to be motivated and encouraged to speak through creating friendly situations with little focus on accuracy. Moreover, more than two thirds $(67.5 \%)$ of the teachers attributed pupils inability to speak English to lack of opportunity to practice 
speaking. The reasons for this lack of opportunities could be due to: firstly, teachers dominated the talk in classroom, classroom observations in this study have confirmed this result that teachers habitually talked for at least half of lesson. Secondly, the majority of the teachers never used visual materials to stimulate speaking. (72.5\%) of the teachers considered large classes is an obstacles to encourage speaking. In the same respect, $70 \%$ of the teachers said that pupils did not participate in speaking activities because the time given is not enough. This could be due to large classes that may impede pupils to have sufficient time to practice speaking. These findings also arrived at by (Sulieman, 2002).

In effective management of speaking can also be attributed to lack of training. More than three quarters $(82.5 \%)$ of the teachers said that they do have enough training in communicative language teaching (CLT), but they put the blame on the syllabuses which are not designed based on communicative principles (teachers contact). The majority (90\%) of the teachers agreed that spoken English should be included in the exam. Moreover, 62.5\% of the teachers agreed that pupils are not motivated to practice spoken English because it is not included in the English language exams. This could also explain why speaking is given less weight compared to other skills, which are examinable.

Teachers' Self Evaluation of Speaking based In-class Tasks - 65\% of the teachers said they always taught imitative drills, $30 \%$ said that they sometimes did this while 5\% rarely used this technique. This indicates that in teaching imitative drills, teachers are concerned more with clarity and accuracy than fluency. Moreover, $87.5 \%$ of the teachers used intensive drills, focused on phonological and grammatical points. Teachers' views were consistent with similar types of drills provided by SPINE, for example: "listen, look and say, listen and repeat, look and say." Though most of the teachers (92.5\%) said that they taught conversation and dialogue as part of speaking activities, SPINE provided no dialogue in SPINE 1, 5 dialogues and very few in the other two books. This shows that teachers do not confine themselves to what is provided in the textbook. They would rather bring their own experience to enrich classroom activities.

With respect to using short answers yes/no, $65 \%$ of the teachers said that they always asked pupils' short questions, which required yes/no answer, $25 \%$ said sometimes used this technique. However, these responses do not agree with Brown (1983) who said that Pupils who are capable of using short answers are going to have trouble when try to speak the FL. Almost half (47.5\%) of the teachers said never asked their pupils to deliver short speech or presentations, $35 \%$ used this technique. This indicates that there is no consistency in using this technique. $45 \%$ of the teachers always asked their pupils to read about interesting topics for classroom speaking activities, $12.5 \%$ said sometimes, the use of these materials (e.g.: literature, newspapers) should be closely associated with the communicative language teaching frame work to help pupils to become thoughtful participants in sociolinguistic ally rich environments that features everyday uses of language. Moreover, $37.5 \%$ of the teachers said they asked pupils to discuss topics before writing composition, 20\% sometimes used this technique, textbook analysis revealed that only reading and few writing from the textbook pupils did inside the classroom. $17.5 \%$ of the teachers led their pupils' access to recorded materials. The only source of listening input was mostly the teachers, because SPINE included no recorded materials, although it is stated as one of the course objective (teachers' book).

Teachers' Attitudes to Teaching Speaking in SPINE - In designing course, material educational objectives have a variety of functions. They serve as guide for the designer's decision about every process in the course design. Taba (1962) identifies two kinds of objective: terminal and developmental objectives. The terminal objective of SPINE is to develop communicative competence (teachers' book). The developmental objectives were stated at the beginning of each lesson. Despite their importance, $47.5 \%$ of the teachers said that the objectives of SPINE did not assist pupils to achieve communicative competence, while one-thirds (30\%) of the teachers considered the general objectives ambiguous. The survey showed that $62.5 \%$, of the teachers said SPINE did not enhance speaking, and $47 \%$ of the teachers said that SPINE did not enhance the oral expression skills. Analytical review of SPINE content, it showed that SPINE rely heavily on structural and functional elements especially book 1,2 and more reading text in SPINE 3. This is not the right content to develop speaking skills (Ishraga, 2001, p. 61). In the same view, $47.5 \%$ of the teachers said that SPINE did not meet the interest of the pupils, which many 
syllabuses writers' consider it as best criteria every syllabus should cater for (Brain, 1998).

$55 \%$ of the teachers agreed that there is no gradual transfer of speaking activities from controlled to less control towards more free activities in SPINE. Analysis of SPINE revealed that SPINE shift from structural element and functions in SPINE 1-2 to more reading texts in SPINE 3. The speaking activities have the same features with no gradation from SPINE 1 to 3.Speaking activities are to be carefully planned in systematic gradation from the mechanical phonological level up to conversation classes. Littlewood (1981), Gower et al. (1995), Broughton et al. (1994) assert that oral production can be divided into three phases: controlled, guided and free. $40 \%$ of the teachers viewed that SPINE needs a companion, while $55 \%$ of the teachers said that materials of SPINE are not authentic. This strongly indicates that materials in SPINE were not adequate and lack to the authenticity. The survey showed $57.5 \%$ of the teachers agreed that activities and exercises in SPINE did not develop speaking skill. This strongly indicates that speaking activities in SPINE are not good. $75 \%$ of the teachers said that SPINE recognized individual differences in achieving communicative competence. Despite their agreements, no material could cater for differences for great number of pupils, because learners differ in learning styles (Brain, 1998).

Also $75 \%$ of the teachers agreed that reading and grammar exercises are more than speaking activities. This strongly implies that little emphasis was given to speaking activities. $75 \%$ of the teachers said that teaching aids offered by SPINE are not enough to develop speaking and $72 \%$ of the teachers said that teaching aids in the SPINE do not express the desired speaking skills. Further, $67.5 \%$ of the teachers said that the technique, design and appearance of the SPINE are not suitable for the speaking skill. The above results indicate that SPINE did not develop speaking, and the layout of the book is not suitable for speaking skill.

\section{Conclusion}

The study aimed at analyzing the speaking activity presented by the text book, and checking teachers' perception towards teaching speaking skills. The study found that the exercises and activities provided by SPINE were of a routine and mechanical type. These activities emphasized repetition and accuracy; ultimately, they did not help pupils to achieve communicative competence in the target language. Also they are not graded from control to creative use of the language. There were no role play, information gap, challengers which are essential features in any communicative syllabus. This finding supports what Ishraga (2001) found that SPINE is not the ideal one for developing speaking .Furthermore, the findings of the present study clearly showed that very little attention had been paid to teaching speaking; it thus came as no surprise that pupils' competence in speaking is very poor. Most of the teachers focus on teaching grammar, pronunciations and reading. It's not enough to focus on teaching grammar rules and new vocabulary. Since it is widely accepted that language is a means of communication, it is possible for the learners of EFL to produce practically all the correct sounds, basic grammatical structure and know the meaning of most words but still unable to put their message across effectively. That requires understanding of when, why and in what ways to produce language (Coulthard, 1985).

Other factors behind less speaking activities could be large classes, teachers found it difficult to arrange their pupils' in circular or U shape positions to facilitate intergroup communicative tasks. In most of Sudanese governmental basic schools, classes' size ranged from 40 to 60 pupils. This crowded class is a problematic, because pupils do not have a sufficient time to practice the language, this may explain why teachers tend to focus on reading and grammar. Specifically, the findings of the present study have practical educational implications in L2 learning and teaching. Teachers man need to understand the pragmatic aspect of speaking in order not only help pupils to speak grammatically but also to interact effectively.

\section{References}

Abdelmuttalib, M. A. (2004). Investigating teaching English alphabet at basic level. Unpublished Masteral thesis, Sudan University of Science \& Technology, Sudan. 
Aisha, B. A. (2006). English language teachers' training at basic level in Khartoum: A critical appraisal. Unpublished Masteral thesis, Sudan University of Science \&Technology, Sudan.

Brain, T. (1998). Materials development in language teaching. Cambridge University Press.

Broughton, G., Brumfit, C., Flaveli, R., Hill, P., \& Pincas, A. (1994). Teaching English as a foreign language. Routledge: London.

Brown, G. (1983). Teaching the spoken language: An approach based on the analysis of conversational English. Cambridge University Press: Cambridge.

Byrne, D. (1981). Teaching oral English. Longman: London.

Gower, R., Philips, D., \& Walters, S. (1995). Teaching practice handbook. Heinemann English Language Teaching. Oxford University.

Ishraga, B. M. (2001). An analysis of the Sudan practical integrated national English textbook (SPINE III). Unpublished Doctoral dissertation, University of Khartoum, Sudan.

Johnson, K., \& Morrow, K. (1982). Communication in the classroom. Longman: Essex.

Kim, H. S. (2003). Korean junior secondary school English teachers' perceptions of speaking assessment. Asian EFL Journals, 5.

Littlewood, W. (1981). Communicative language teaching. Cambridge: Cambridge University Press.

Littlewood, W. (1984). Foreign and second language learning. Cambridge: Cambridge University Press. Lyons, J. (1986). Introduction to theoretical linguistics. Cambridge: Cambridge University Press.

Mackey, W. (1965). Language teaching analysis. Cambridge: Cambridge University Press.

Mc Cready, G. (1975). Developing a lesson a round dialogue forum. Sudan: The Art of Education.

Ministry of Education. (1992). The SPINE series, Teacher's book 1, 2, 3. Khartoum: Ministry of Education.

Morrow, K. (1981). Principles of communicative methodology. Ink: Johnson.

Nafisa, M. K. (2004). Second language learners' error in tenses in secondary school. Unpublished Masteral thesis, University of Juba, Sudan.

Paulston, C. (1972). Structural pattern drills: A classification. In H. Allen \& R. Campbell (Eds.), Teaching English as a second language: A book of Readings (2nd ed., pp. 129-138). New York: McGraw Hill.

Suleiman, N. (2002). Stimulation of oral communication in EFL: A study of English language major in four Sudanese universities. Unpublished Doctoral dissertation, University of Khartoum, Sudan.

Taba, H. (1962). Curriculum development: Theory and practice. New York: Harcourt Brace \& World Inc. 
Ahmed, S. H. A. 